\title{
Prevalence and risk factors of hepatitis B and C virus infections in an impoverished urban community in Dhaka, Bangladesh
}

\author{
Hasan Ashraf ${ }^{*}$, Nur H Alam¹, Christian Rothermundt ${ }^{2}$, Abdullah Brooks ${ }^{1,3}$, Pradip Bardhan ${ }^{1}$, Lokman Hossain ${ }^{1}$, \\ Mohammed A Salam, Mohammed S Hassan ${ }^{4}$, Christoph Beglinger ${ }^{2}$, Niklaus Gyr ${ }^{2}$
}

\begin{abstract}
Background: Viral hepatitis is a serious global public health problem affecting billions of people globally, and both hepatitis $B$ virus ( $\mathrm{HBV}$ ) and hepatitis $\mathrm{C}$ virus ( $\mathrm{HCV}$ ) infections are rapidly spreading in the developing countries including Bangladesh due to the lack of health education, poverty, illiteracy and lack of hepatitis B vaccination. Also there is lack of information on their prevalence among the general population. So, a population-based serological survey was conducted in Dhaka to determine the prevalence and risk factors of HBV and HCV infections.

Methods: Healthy individuals were selected for demographic and behavioural characteristics by stratified cluster sampling and blood tested for hepatitis B surface antigen ( $\mathrm{HBsAg}$ ), antibody to HBV core antigen (anti-HBC), and anti-HCV antibodies (anti-HCV).

Results: From June 2005-November 2006, 1997 participants were screened for HBsAg, anti-HBC and anti-HCV, 738 (37\%) were males with mean (SD) age of 24 (14) years. HBV-seropositivity was documented in 582 (29\%) participants: 14 (0.7\%) were positive for HBsAg, 452 (22.6\%) for anti-HBc and 116 (5.8\%) for both HBsAg and anti$\mathrm{HBC}$. Four (0.2\%) participants were positive for anti-HCV, and another five (0.3\%) for both anti-HBC and anti-HCV. Ninety-six/246 (39\%) family members residing at same households with HBsAg positive participants were also HBVseropositive [74 (30.1\%) for anti-HBC and 22 (8.9\%) for both HBsAg and anti-HBC], which was significantly higher among family members (39\%) than that of study participants (29\%) (OR 1.56; $p<0.001$ ). In bivariate analysis, HBVseropositivity was significantly associated with married status (OR 2.27; $\mathrm{p}<0.001)$, history of jaundice $(\mathrm{OR} 1.35 ; \mathrm{p}=$ 0.009), surgical operations (OR 1.26; $p=0.04$ ), needle-stick injuries (OR 2.09; $p=0.002$ ), visiting unregistered healthcare providers (OR 1.40; $p=0.008$ ), receiving treatment for sexually transmitted diseases (STD) (OR 1.79; $p=0.001$ ), animal bites (OR 1.73; $p<0.001)$; ear-nose-body piercing in females (OR 4.97; $p<0.001)$; circumcision (OR 3.21; $p<$ 0.001 ), and visiting community barber for shaving in males (OR 3.77; $p<0.001$ ). In logistic regression analysis, married status (OR 1.32; $p=0.04$ ), surgical operations (OR 1.39; $p=0.02$ ), animal bites (OR 1.43; $p=0.02$ ), visiting unregistered health-care providers (OR 1.40; $p=0.01$ ); and ear-nose-body piercing in females (OR 4.97; $p<0.001$ ) were significantly associated with HBV-seropositivity.

Conclusions: The results indicate intermediate level of endemicity of HBV infection in Dhaka community, with much higher prevalence among family members of HBsAg positive individuals but low prevalence of HCV infections, clearly indicating need for universal hepatitis B vaccination. The use of disposable needles for ear-nosebody piercing need to be promoted through public awareness programmes as a preventive strategy.
\end{abstract}

\footnotetext{
* Correspondence: ashrafh@icddrb.org

${ }^{1}$ ICDDR,B (International Centre for Diarrhoeal Disease Research, Bangladesh),

68 Shaheed Tajuddin Ahmed Sarani, Mohakhali, Dhaka 1212, Bangladesh
} 


\section{Background}

Viral hepatitis is a serious public health problem affecting billions of people globally. Caused mainly by hepatitis viruses $\mathrm{A}, \mathrm{B}, \mathrm{C}, \mathrm{D}$ and $\mathrm{E}$, and rarely by cytomegalovirus (CMV), Epstein-Barr virus (EBV) and fungal infections, the spectrum of hepatitis range from sub-clinical to milder and life threatening illness including hepatocellular carcinoma [1,2]. Globally two billion people are infected with HBV, and 350 millions of them have chronic (lifelong) infections, who are at high risk of death from liver cirrhosis and liver cancer that kill more than one million people globally each year [3]. In the Middle East and Indian sub-continent, HBV infection is of intermediate endemicity with chronic HBV carriage rate of $2-5 \%$ among general population [3]. In Bangladesh, there is paucity of information on the prevalence of $\mathrm{HBV}$ infections among general population and majority of the previous studies were conducted in selected group of people with higher risk factors such as blood donors, drug addicts, commercial sex workers (CSWs) or hospitalised patients [4-8]. However, a recent report showed 5.5\% HBsAg positivity among the general population living in Savar, a semi-urban area on the outskirts of Dhaka [9]. Although HBsAg is the most reliable biological biomarker of HBV infection, and the anti-HBc antibody is an important marker for surveying the burden of HBV infection as it persists even after resolution of infection, and thus identifies both past and current HBV infection [10]. As majority of the previous studies in Bangladesh examined only the prevalence of HBsAg [2,4-7,11-16] and most of them were conducted in selected group of people with higher risk factors, we decided to estimate the prevalence of both HBsAg and anti-HBc among the general population of Dhaka, Bangladesh.

$\mathrm{HCV}$ infections is also a major global health problem with an estimated 170 million people chronically infected and 3-4 million people get new infections each year [17]. HCV infections lead to acute hepatitis in $20 \%$ cases, and chronic hepatitis in $50-80 \%$ cases, of whom $10-20 \%$ develop liver cirrhosis [17-20] and 1-5\% develop liver cancer in 20-30 years [17]. The prevalence of HCV infection varies throughout the world with significant regional and ethnic differences. The highest number reported from Egypt following parenteral antischistosomal therapy with a prevalence of anti-HCV of $6-28 \%$ (mean 22\%) depending on the regions [21]. Although some risk factors for acquiring $\mathrm{HCV}$ infections are present in $50 \%$ cases, no recognizable transmission factor could be identified in the remaining $50 \%$ [17,22]. As there is also lack of information on the prevalence of $\mathrm{HCV}$ infection among the general population and nearly all previous studies were conducted in selected group of people [8,23-25], we also decided to estimate the prevalence of anti-HCV in the same population.

It is evident that HBV and $\mathrm{HCV}$ infections are both major global health problems, and they are rapidly spreading in developing countries due to the lack of health education, poverty, illiteracy and lack of hepatitis $B$ vaccination. As many chronically infected individuals remain asymptomatic, and thus undetected for many years, we planned this population-based serological study to determine the prevalence of HBsAg, anti-HBc, and anti-HCV among all age groups and to identify the possible risk factors for acquiring the infections. We hoped that the findings might guide eventually the development, adaptation, and evaluation of prevention strategies.

\section{Methods \\ Study site}

The study was conducted in Kamalapur, a densely populated community in urban Dhaka, the capital city of Bangladesh. The International Centre for Diarrhoeal Disease Research, Bangladesh (ICDDR, B) has been using this as its first urban field site since 1998. It is an impoverished area comprised of seven communities in four municipal wards with 200,000 residents in an area of $4 \mathrm{~km}^{2}\left(29,663\right.$ persons $\left./ \mathrm{km}^{2}\right), 11.2 \%$ of whom are under-5 children, with a mean (range) house hold size of 4 ( 1 to 20 ) persons. They have a median monthly household income of US $\$ 50$. Kamalapur is divided into seven geographical strata and 450 clusters, each with approximately 100 households. The community had all the potential reported risk factors, such as overcrowding, low income, poor sanitation for high disease burden of infectious diseases such as diarrhea, and pneumonia $[26,27]$ and hepatitis.

\section{Sample size}

Assuming that $6 \%$ of the population will have a HBsAg positive status with $1 \%$ precision and $95 \%$ confidence limit, we estimated the sample size to be 1955 . For $\mathrm{HCV}$, we assumed that $5 \%$ of the population will have an anti-HCV positive status with 1\% precision and $95 \%$ confidence limit, we estimated the sample size to be 1825. Assuming a refusal rate of $10 \%$, we determined the sample size to be 2000. To get sufficient number of people to detect the above mentioned prevalence, we considered Kamalapur, Dhaka, as the population suitable for this study.

\section{Randomization}

A population based, cross-sectional survey was conducted in 2000 individuals, aged 0-60 years during 20052006. For achieving this sample, all the 450 geographical 
clusters of Kamalapur were selected using random sampling. The first household of the cluster was chosen randomly and if a locked house was encountered, then the next household in same direction replaced that.

\section{Study procedure}

The trained field research assistants (FRAs) visited the selected households in accordance with the randomisation list and approached the head of the family. They explained the purpose and objective of the study and obtained written informed consent from study participants, or parents for eligible children. They administered a pre-tested questionnaire to the participants at a mutually agreed date at the clinic, when a research physician collected $4 \mathrm{ml}$ of blood from the antecubital veins under aseptic conditions. The blood specimens were centrifuged at the clinic within 6 hours and separated sera were transported to the Dhaka Hospital of ICDDR, B, and stored at $-20^{\circ} \mathrm{C}$ in aliquots. For diagnosis of $\mathrm{HBV}$ infection, HBsAg and anti-HBc were determined using commercially available enzyme-linked immunosorbent assay (ELISA) kits (Manufacturer: DiaSorin S. A., Italy). For diagnosis of HCV infection, anti-HCV antibody was detected using a third-generation ELISA kit (Manufacturer: DiaSorin S. A., Italy). After collection of blood samples, the research physician interviewed the participants (parents if the participant was a minor) in a private set up within the clinic to collect their socio-demographic characteristics including age, gender, years of education, socio-economic status, occupation, income, and marital status by using a structured questionnaire. They were also asked about the type of health care providers they consulted for health problems, history of jaundice, history of taking injections, previous surgical procedures, frequency of dental visits, receiving blood or blood products, history of current/past use of intravenous drugs, siblings, history of tattooing; ear-nose-body piercing in females, and circumcision and visiting community barbers for shaving in males. Some questions about sexual behaviour such as having multiple sexual partners, having received treatment for STD were asked to participants 18 years of age or older by research physician of the same sex. The study was approved by the Research and Ethical Review Committees of ICDDR, B.

The laboratory test results were kept confidential and the research physician shared the results with the participants. Infected individuals were provided with appropriate information on the prevention of spread of these infections to others, and referred them to the nearest public health care facilities.

\section{Serological tests}

We only performed $\mathrm{HBsAg}$, anti-HBc, and anti-HCV to reduce the laboratory test costs.

\section{HBsAg}

is the serologic hallmark of HBV infection. It appears in serum 1-10 weeks after an acute exposure to HBV, prior to the onset of hepatitic symptoms. The sensitivity of HBsAg is $100 \%$, the specificity is $99.7 \%$, and the limit of detection is 0.05 PEI units $/ \mathrm{ml}$. The lower limit of detection, PEI unit was explained as the analytical sensitivity that may be expressed as the limit of detection, which is the minimal amount of specific analyte precisely detectable by the assay. A conversion of 0.05 PEI units $/ \mathrm{ml}$ to international unit (IU) values was evaluated by testing HBsAg international reference material from World Health Organization NIBSC $1^{\text {st }}$ International Standard, code 80/549; (HBsAg, subtype $a d$ ) and limit of detection was found to be $0.05 \mathrm{IU} / \mathrm{ml}$. When the same protocol was used with Paul-Ehrlich-Institute (Germany), HBsAg reference preparation (subtypes $a d$, ay), the detection limit came to 0.03 PEI units $/ \mathrm{ml}$. If the infection is selflimited, HBsAg disappears in most patients before the serum hepatitis B surface antibody (anti-HBs) can be detected. Persistence of HBsAg for more than six months implies chronic infection.

\section{Anti-HBc}

identifies individuals with both current and past HBV infection (prevalence). The sensitivity of anti-HBc is $100 \%$, the specificity is $99.83 \%$, and the limit of detection is $<0.5$ PEI units/ml. Almost all HBV-infected people usually develop anti-HBc. Detection of anti-HBc indicates exposure to $\mathrm{HBV}$, which may be acute, chronic, or resolved infection. Fourteen (0.7\%) study subjects were expressing HBsAg positive, but negative for anti-HBc. Although rare, this serological profile of $\mathrm{HBsAg}$ positive, but anti-HBc negative is not that exceptional. In addition to the diagnostic kits efficacy, the immunosuppressive state of the subject may also contribute to such profile [28].

\section{Anti-HCV}

The discovery of $\mathrm{HCV}$ in 1989 led to the development of an antibody diagnostic assay (anti-HCV) based on viral recombinant peptides. The third generation assays (ELISA-3) have been introduced incorporating antigens from putative neucleocapsid, NS3, NS4, and NS5 regions, and become positive in 2-3 weeks after the infection [29]. They are currently the most widely used screening tests for HCV and are more sensitive and specific than earlier generation tests in screening blood donors [30]. Detection of anti-HCV indicates present or previous $\mathrm{HCV}$ infection but cannot discriminate acute from chronic or resolved HCV infection [31].

\section{Statistical Analysis}

All data were analysed using Statistical Package for Social Sciences (SPSS) version 10.0 [32]. The analysis was carried out at three levels of descriptive, bivariate 
and logistic regression analysis. Descriptive statistics of socio-demographic variables and other characteristics of the sampled population were computed. Means and SD were calculated for quantitative variables and proportions for categorical variables. Percentage with 95\% confidence interval (CI) was used to describe the prevalence. OR and 95\% CI was calculated for each association. Associations among independent variables were assessed using appropriate tests, such as $x^{2}$ or Fisher's exact tests, when indicated before performing logistic regression analysis. Multiple logistic regression models were used to examine the association between independent variables and the main outcome variable, $\mathrm{HBV}$-seropositivity, while controlling for the effects of other covariates. All variables which were associated with outcome in bivariate analysis were included in the model. In logistic model, reference category $(\mathrm{OR}=1)$ for OR estimate was $\mathrm{HBV}$-negative participants. A probability of $<0.05$ was considered as statistical significant. The final logistic regression model was obtained by forward selection based on single variables and their possible interactions. Given small number of hepatitis $C$ infections, no tests of association could be performed.

\section{Results}

From June 2005 to November 2006, 2004 subjects were initially selected for the study, of whom 1997 participants were enrolled into the study, mostly young adults, 738 (37\%) were males and 1259 (63\%) were females, with a mean (SD) age of 24 (14) years. Seven subjects were not enrolled as we failed to confirm the serological diagnosis. The evidence for current or previous HBV infection was documented in 582 (29\%) participants with a male to female ratio of 40:60 and a mean (SD) age of 28 (13) years. HBsAg was positive in $14(0.7 \%)$ participants, antiHBc was positive in 452 (22.6\%) participants, and both HBsAg and anti-HBc were positive in 116 (5.8\%) participants (Table 1$)$. Four (0.2\%) participants were positive for anti-HCV, and another five $(0.3 \%)$ for both anti-HBc and anti-HCV (Table 1). The HBV positivity was significantly more among females than male participants (40\% vs. 10\%) (OR 5.75; p < 0.001). The HBV positivity among under-5 children were 60/208 (28.8\%): HBsAg was positive in 5/208 $(2.4 \%)$ children, anti-HBc was positive in 34/208 (16.3\%), and both HBsAg and anti-HBc were positive in $21 / 208(10 \%)$ children (Table 1$)$. The anti$\mathrm{HBc}$ positivity was significantly less among under- 5 children than that of study participants (16.3\% vs. $22.6 \%)$ (OR 1.47; $\mathrm{p}<0.01$ ). After receiving laboratory results, 246 family members residing at the same household as that of the study participants' positive for HBsAg were similarly studied. In total, 96/246 (39\%) of them were HBV-seropositive with a male to female ratio of 45:55 and a mean (SD) age of 21 (16) years: 74 (30.1\%) were positive for anti-HBc, and $22(8.9 \%)$ were positive for both HBsAg and anti-HBc (Figure 1). In fact, the prevalence of HBV infection among the family members (96/ 246 ; 39\%) was significantly higher than that of the study participants $(582 / 1997$; 29\%) (OR 1.56; p < 0.001). Hepatitis $B$ vaccination was found to be protective against HBV infection [only 10/582 (1.7\%) of the HBV positive participants were vaccinated in contrast to $66 / 1406$ (4.7\%) of the HBV negative participants were vaccinated] (OR 2.82; $\mathrm{p}=0.001)$.

\section{Risk factors for HBV-seropositivity}

In bivariate analysis, $\mathrm{HBV}$-seropositivity (including HBsAg positive, or anti-HBc positive, or both $\mathrm{HBsAg}$ and anti-HBc positive participants) was significantly associated with a variety of sociodemographic and behavioral independent variables, such as married status (OR 2.27; $\mathrm{p}<0.001$ ), history of jaundice (OR 1.35; $\mathrm{p}=$ 0.009 ), surgical operations (OR 1.26; $\mathrm{p}=0.04$ ), needlestick injuries (OR 2.09; $\mathrm{p}=0.002$ ), visiting unregistered health-care providers (OR 1.40; $\mathrm{p}=0.008$ ), receiving treatment for STD (OR 1.79; p = 0.001), animal bites (OR 1.73; $\mathrm{p}<0.001$ ); ear-nose-body piercing in females (OR 4.97; $\mathrm{p}<0.001$ ); circumcision (OR 3.21; $\mathrm{p}<0.001$ ) and visiting community barber for shaving in males (OR 3.77; p < 0.001) (Table 2).

After adjusting for potential confounding effects in the logistic regression analysis, married status (OR 1.32; $\mathrm{p}=0.04)$, surgical operations (OR 1.39; $\mathrm{p}=0.02)$, animal bites (OR 1.43; $\mathrm{p}=0.02$ ), visiting unregistered healthcare providers (OR 1.40; $\mathrm{p}=0.01$ ); and ear-nose-body piercing in females (OR 4.97; $\mathrm{p}<0.001$ ) remained

Table 1 Groups of study participants and family members based on the serological test results

\begin{tabular}{|c|c|c|c|c|}
\hline Positive test results & $\begin{array}{l}\text { Study participants } \\
(\mathrm{n}=1997)\end{array}$ & $\begin{array}{l}\text { Under-5 children } \\
(\mathrm{n}=208)\end{array}$ & $\begin{array}{l}\text { Family members } \\
(\mathrm{n}=246)\end{array}$ & Interpretation \\
\hline 1. $\mathrm{HBsAg}$ & $14(0.7 \%)$ & $5(2.4 \%)$ & 0 & Acute or chronic HBV infection \\
\hline 2. Anti-HBC & $452(22.6 \%)$ & $34(16.3 \%)$ & $74(30 \%)$ & $\begin{array}{l}\text { Exposure to HBV, which may be acute, chronic or } \\
\text { resolved infection }\end{array}$ \\
\hline 3. Both $\mathrm{HBsAg}$ and anti-HBC & $116(5.8 \%)$ & $21(10 \%)$ & $22(8.9 \%)$ & Acute or chronic HBV infection \\
\hline 4. Anti-HCV & $4(0.2 \%)$ & 0 & 0 & Present or previous HCV infection \\
\hline 5. Both anti-HBC and anti-HCV & $5(0.3 \%)$ & 0 & $1(0.4 \%)$ & Mixed HBV and HCV infections \\
\hline
\end{tabular}




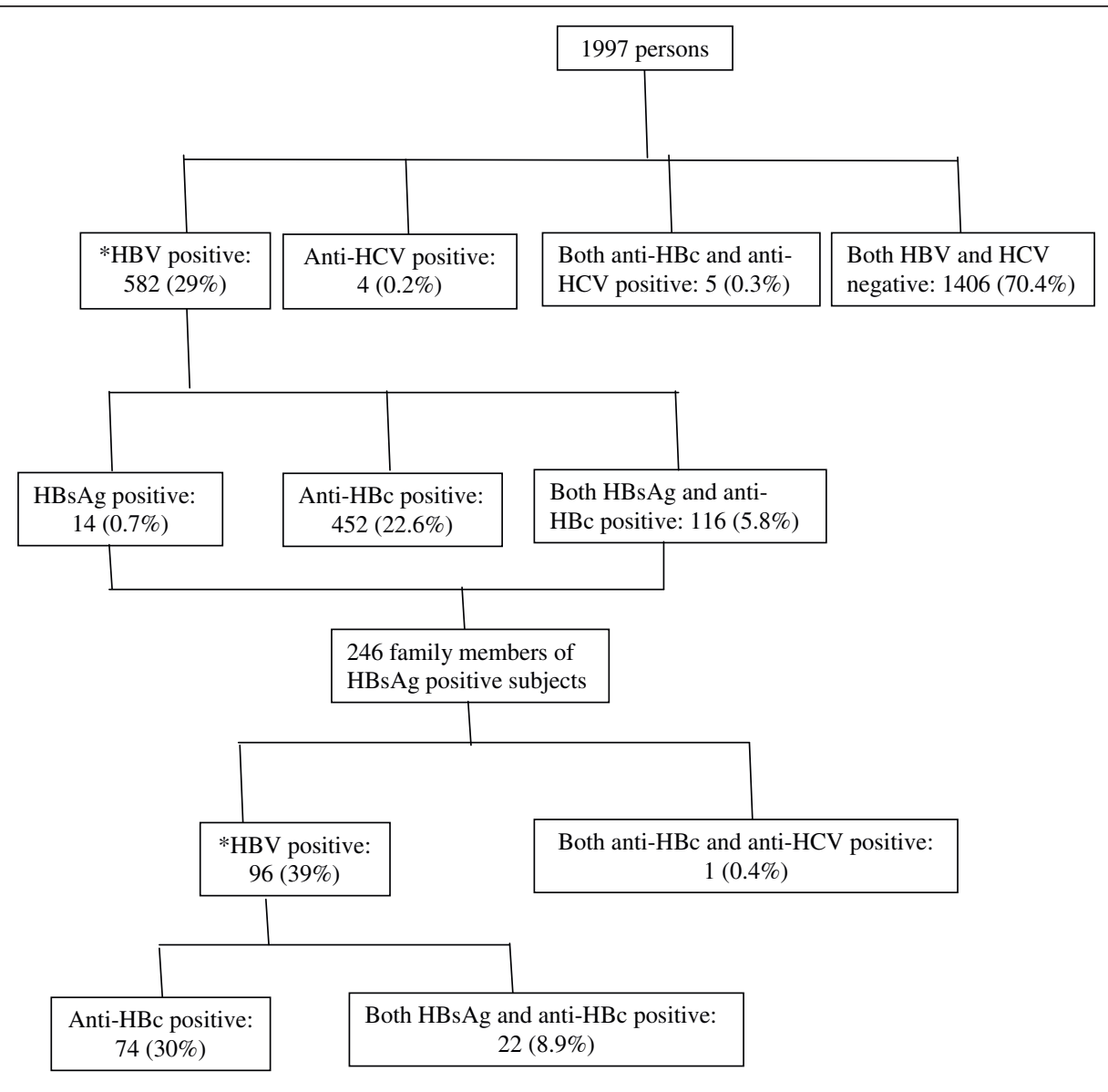

(Note: *HBV-seropositivity includes HBsAg positive/anti-HBc positive/both HBsAg and anti-

HBc positive study participants)

Figure 1 Study Profile

independent determinants of HBV-seropositivity (Table 3). In the above regression model, both age and sex were retained as covariates to control their influence on other covariates.

\section{Discussion}

Although prevalence studies are not always easily undertaken in the developing countries such as Bangladesh due to high cost, we made efforts to prospectively estimate the prevalence of HBV and HCV infections among a population living at Kamalapur, a densely populated community in Dhaka, the capital city of Bangladesh.

The results of our study suggest a high HBV exposure among our study population. The HBsAg prevalence of $6.5 \%$ among our study population is within the range of $2-7 \%$, reported by previous studies from selective population of Dhaka: 3\% among healthy adults and children [33] and 3.5\% among pregnant women [5]; however, much lower rate $(0.8 \%)$ was observed among school children [16]. The prevalence was also within the same range as reported from some high-risk groups from Dhaka: $4.4 \%$ among non-injectable drug users (nonIDUs) and 6.2\% in injectable drug users (IDUs) [24]; and $5.9 \%$ among truck drivers and helpers [34]. The higher rates among our study population could be attributed to the general lack of proper health care because of deprived socio-economic status (monthly household income of US \$50) and less public health awareness about the transmission of HBV infection as well as the lack of hepatitis B vaccination in the community. Our prevalence was similar (6.5\% vs. $6.4 \%)$ to that reported from the Rangpur district of Bangladesh [13]. However, higher prevalence has also been reported among the high-risk groups of Dhaka: 7.6\% among women at a STD clinic [23]; 8\% among IDUs [6]; 8.6\% among surgically operated patients [7]; 9.7\% among CSWs [8]; 19\% among hepatitis patients [2]; and $47 \%$ among hepatocellular carcinoma patients [14]. 
Table 2 Bivariate analysis for significant risk factors for *HBV-seropositivity

\begin{tabular}{|c|c|c|c|c|}
\hline Risk factors & *HBV positive $n=582(100 \%)$ & HBV negative $n=1406$ (100\%) & Odds Ratio $(95 \% \mathrm{Cl})$ & $p$-value \\
\hline \multicolumn{5}{|c|}{ 1. Marital status } \\
\hline Un-married & $200(34.4)$ & $764(54.3)$ & 1.0 & \\
\hline Married & $382(65.6)$ & $642(45.7)$ & $2.27(1.85-2.79)$ & $<0.001$ \\
\hline \multicolumn{5}{|c|}{ 2. History of jaundice } \\
\hline No & $431(74.1)$ & $1116(79.4)$ & 1.0 & \\
\hline Yes & $151(25.9)$ & $290(20.6)$ & $1.35(1.07-1.70)$ & 0.009 \\
\hline \multicolumn{5}{|c|}{ 3. Previous surgery } \\
\hline No & $431(74.1)$ & $1101(78.3)$ & 1.0 & \\
\hline Yes & $151(25.9)$ & $305(21.7)$ & $1.26(1.00-1.59)$ & 0.04 \\
\hline \multicolumn{5}{|c|}{ 4. Circumcision in males only $(n=734)$} \\
\hline No & $37(15.9)$ & $190(37.8)$ & 1.0 & \\
\hline Yes & $195(84.1)$ & $312(62.2)$ & $3.21(2.13-4.86)$ & $<0.001$ \\
\hline \multicolumn{5}{|c|}{ 5. Needle-stick injuries } \\
\hline No & $550(94.5)$ & $1368(97.3)$ & 1.0 & \\
\hline Yes & $32(5.5)$ & $38(2.7)$ & $2.09(1.26-3.47)$ & 0.002 \\
\hline \multicolumn{5}{|c|}{ 6. Ear-nose-body piercing in females only $(n=1254)$} \\
\hline No & $14(4)$ & $155(17.1)$ & 1.0 & \\
\hline Yes & $336(96)$ & $749(82.9)$ & $4.97(2.76-9.10)$ & $<0.001$ \\
\hline \multicolumn{5}{|c|}{ 7. Animal bites } \\
\hline No & $451(77.5)$ & $1204(85.6)$ & 1.0 & \\
\hline Yes & $131(22.5)$ & $202(14.4)$ & $1.73(1.34-2.23)$ & $<0.001$ \\
\hline \multicolumn{5}{|c|}{ 8. Visiting community barber for shaving in males only $(n=734)$} \\
\hline No & $64(27.6)$ & $296(59)$ & 1.0 & \\
\hline Yes & $168(72.4)$ & $206(14)$ & $3.77(2.65-5.37)$ & $<0.001$ \\
\hline \multicolumn{5}{|c|}{ 9. Visiting unregistered health care providers } \\
\hline No & $98(16.8)$ & $310(22.0)$ & 1.0 & \\
\hline Yes & $484(83.2)$ & $1096(78.0)$ & $1.40(1.08-1.81)$ & 0.008 \\
\hline \multicolumn{5}{|c|}{ 10. Receiving treatment for STD } \\
\hline No & $528(90.7)$ & $1330(94.6)$ & 1.0 & \\
\hline Yes & $54(9.3)$ & $76(5.4)$ & $1.79(1.23-2.61)$ & 0.001 \\
\hline
\end{tabular}

(Note: *HBV-seropositivity includes $\mathrm{HBsAg}$ positive/anti-HBc positive/both $\mathrm{HBsAg}$ and anti-HBc positive study participants)

Table 3 Multiple logistic regression analysis for being *HBV-seropositive

\begin{tabular}{|c|c|c|c|c|}
\hline Risk factors & ${ }^{*} \mathrm{HBV}$ positive $\mathrm{n}=582(100 \%)$ & HBV negative $n=1406(100 \%)$ & $\begin{array}{l}\text { Adjusted Odds Ratio } \\
(95 \% \mathrm{Cl})\end{array}$ & $p$-value \\
\hline 1. Married status & $382(65.6)$ & $642(45.7)$ & $1.32(1.00-1.73)$ & 0.046 \\
\hline 2. Previous surgery & $151(25.9)$ & $305(21.7)$ & $1.39(1.05-1.82)$ & 0.02 \\
\hline $\begin{array}{l}\text { 3. Ear-nose-body piercing in females } \\
(n=1254)\end{array}$ & 336/1085 (31) & $14 / 169(8.3)$ & $4.97(2.76-9.10)$ & $<0.001$ \\
\hline 4. Animal bites & $131(22.5)$ & $202(14.4)$ & $1.43(1.04-1.96)$ & 0.024 \\
\hline 5. Visiting unregistered health-care providers & $484(83.2)$ & $1096(78.0)$ & $1.40(1.08-1.82)$ & 0.012 \\
\hline
\end{tabular}

(Note: *HBV-seropositivity includes $\mathrm{HBsAg}$ positive/anti-HBc positive/both $\mathrm{HBsAg}$ and anti-HBc positive study participants.

Initial models included the variables age, sex, married status, history of jaundice, surgical operation, circumcision, needle-stick injuries, animal bites, visiting unregistered health care providers, receiving treatment for STD, ear-nose-body piercing in females, circumcision, and visiting community barber for shaving in males. Significant factors were retained in the final model) 
The prevalence of anti-HBc in our study population was similar $(22.6 \%$ vs. $21.1 \%)$ to that reported from healthy adults and children [33] but lower than that reported from the high-risk groups of Dhaka: $24.1 \%$ in non-IDUs and $31.8 \%$ in IDUs [24]; 35.2\% among women at a STD clinic [23]; $48.1 \%$ among truck drivers and helpers [34]; 49.3\% among women living near a truck stand [25]; and 73\% among CSWs [8].

The $0.2 \%$ prevalence of anti-HCV observed in our study population is lower than that reported from highrisk groups of Dhaka: $0.8 \%$ among truck drivers and helpers [34]; 0.9\% among women at a STD clinic [23]; $1.6 \%$ among women living near a truck stand [25]; $5.8 \%$ in non-IDUs and $24.8 \%$ in IDUs [24]; and $13 \%$ among hepatitis patients [2].

The intermediate rate of chronic HBV carriage of around 3\% was observed in most general populations (clinics, villagers), suggesting that this population would benefit from universal hepatitis B vaccination [11]. In 2004, the Government of Bangladesh and UNICEF have introduced the hepatitis B vaccine into the Expanded Programme on Immunization (EPI) against six infectious diseases. The successful continuation of the programme is expected to reduce chronic HBV infections in the next generations. Since $90 \%$ of the HBV infected older children and adults successfully clear the infection and do not become chronic carriers, the prevalence of HBsAg alone might not describe the total burden of HBV infections. Therefore, estimation of the prevalence of anti$\mathrm{HBc}$, in addition to the estimation of the prevalence of HBsAg which is the most reliable biological biomarker of $\mathrm{HBV}$ infection, is much more informative about indicator of HBV disease burden among the population. This probably accounts for our higher anti-HBc (22.6\%) than HBsAg (6.5\%) seropositivity rates (Figure 1).

There are some limitations of our study. First, we did not perform some diagnostic tests for HBV, e.g. anti-HBc $\mathrm{IgM}$, the presence of which indicates acute infection; and anti-HBs that differentiates susceptible persons from those immune persons, which can be due either to natural infection or hepatitis B vaccination. Second, we did not perform some diagnostic tests for HCV, e. g. recombinant immunoblot assay (RIBA) to confirm HCV exposure, or polymerase chain reaction (PCR) to detect $\mathrm{HCV}$ infected individuals. All the above limitations are mainly due to study cost constraints, mostly related to laboratory tests. The third limitation is that the study was conducted in a single population in Dhaka, and may not reflect all of Bangladesh, although the literature we have cited suggests that it should. The fourth limitation is the selection of Kamalapur as the study site, as the activities of ICDDR,B might influence the prevalence of $\mathrm{HBV}$ and $\mathrm{HCV}$, which might be a biased location because the people of this area might have altered KAP (knowledge, attitude and performance) regarding infectious diseases due to prolonged presence of ICDDR,B team and their health education. A final limitation is the relatively short observation window, which may have missed important secular trends in the background prevalence of both the hepatitis $B$ and $C$ viruses.

\section{Conclusions}

The results of our study indicate intermediate level of endemicity of HBV infection such as overall intermediate prevalence of HBsAg; but high anti-HBc, indicating that the members of this urban community are highly exposed to a high prevalence of the hepatitis B virus, which may be acute, chronic or resolved, in an urban community in Dhaka, Bangladesh. We also noted higher prevalence among the family members residing at the same household of that of the HBsAg positive individuals, suggesting likely intra-household transmission. However, we observed a much lower prevalence of $\mathrm{HCV}$ infections in the same community. We also identified some independent risk factors, which could help health care providers and policy makers in designing and initiating effective preventive programmes. The findings also highlight the need for prevention and control of HBV infection in Bangladesh by implementing universal hepatitis $B$ vaccination and creating public awareness to promote the use of disposable needles for ear-nose-body piercing.

Future follow-up studies are required to confirm the family clustering effect of HBV infection as observed in Korea [35], and to better define the transmission dynamics, and to identify their common risk factors for acquiring HBV infection by comparing family members of HBsAg positive participants with those who are negative for the tests. Such a study is planned to be conducted for the same community in Dhaka. Further, more long-term population-based surveillance studies, with extended serology of HBV infection, are needed to more accurately assess the hepatitis B true disease burden in Bangladesh, the impact of vaccination, and to guide prioritization of scarce health care resources.

\section{Abbreviations}

ICDDR,B: International Centre for Diarrhoeal Disease Research, Bangladesh; HBV: Hepatitis B virus; HCV: Hepatitis C virus; HBsAg: Hepatitis B surface antigen; Anti-HBC: Antibody to hepatitis B core antigen; Anti-HCV: Anti-HCV antibody; SD: Standard deviation; OR: Odds ratio; STD: Sexually transmitted diseases; CMV: Cytomegalovirus; EBV: Epstein-Barr virus; CSWs: Commercial sex workers; FRAs: Field research assistants; ELISA: Enzyme-linked immunosorbent assay; SPSS: Statistical Package for Social Sciences; Cl: Confidence Interval; Anti-HBs: Hepatitis B surface antibody; PEl: Paul-EhrlichInstitute; Non-IDUs: Non-injectable drug users; IDUs: Injectable drug users; UNICEF: The United Nations International Children's Fund; EPI: Expanded Programme on Immunization; RIBA: Recombinant immunoblot assay; PCR: Polymerase chain reaction; KAP: Knowledge, attitude and performance.

\section{Acknowledgements}

The study was funded by the ICDDR,B, the Gastroenterology Science Foundation, University of Basel (GR-409) and the Velux-Foundation, 
Switzerland. ICDDR,B acknowledges with gratitude the commitment of the Gastroenterology Science Foundation and the Velux-Foundation to the Centre's research efforts. ICDDR,B also gratefully acknowledges the following donors which provide unrestricted support to the Centre's research efforts: Australian Agency for International Development (AusAID), Government of the People's Republic of Bangladesh, Canadian International Development Agency (CIDA), Embassy of the Kingdom of the Netherlands (EKN), Swedish International Development Cooperation Agency (Sida), Swiss Agency for Development and Cooperation (SDC), and Department for International Development, UK (DFID). The authors are grateful to Drs. Mahbubur Rahman and Khalequzzaman for their excellent review of the manuscript.

\section{Author details}

'ICDDR,B (International Centre for Diarrhoeal Disease Research, Bangladesh), 68 Shaheed Tajuddin Ahmed Sarani, Mohakhali, Dhaka 1212, Bangladesh. ${ }^{2}$ University of Basel, Petersgraben 4, CH-4031, Basel, Switzerland. ${ }^{3}$ Johns Hopkins Bloomberg School of Public Health, 615 N. Wolfe Street, Baltimore, MD 21205, USA. ${ }^{4}$ BIRDEM (Diabetic Hospital), 122, Kazi Nazrul Islam Avenue, Dhaka 1000, Bangladesh.

\section{Authors' contributions}

$H A, C R, N G$ conceived the idea; HA, CR, NG, NHA, LH contributed to the study data interpretation; HA, MAS, NG wrote the paper. HA, CR, NG, NHA, $L H, M A S, W A B, P B, M S H, C G$ critically analyzed and approved the final manuscript.

\section{Competing interests}

The authors declare that they have no competing interests.

Received: 24 February 2010 Accepted: 15 July 2010

Published: 15 July 2010

\section{References}

1. Zuckerman AJ: Prevention of primary liver cancer by immunization. $N$ Engl J Med 1997, 336:1906-7.

2. Khan WI, Sultana R, Rahman M, Akhter H, Haq JA, Ali L, Mohsin MA, Khan AK: Viral hepatitis: recent experiences from serological studies in Bangladesh. Asian Pac J Allergy Immunol 2000, 18:99-103.

3. Hepatitis B: 2008 [http://www.who.int/mediacentre/factsheets/fs204/en].

4. Islam MN, Islam KM, Islam N: Hepatitis-B virus infection in Dhaka, Bangladesh. Bangladesh Med Res Counc Bull 1984, 10:1-6.

5. Rumi MA, Begum K, Hassan MS, Hasan SM, Azam MG, Hasan KN, Shirin M, Khan AK: Detection of hepatitis B surface antigen in pregnant women attending a public hospital for delivery: implication for vaccination strategy in Bangladesh. Am J Trop Med Hyg 1998, 59:318-22.

6. Mustafa M, Islam MN, Rahman M, Salauddin AK: Prevalence of hepatitis B surface antigen ( $\mathrm{HBsAg})$ among parenteral drug abusers at Dhaka. Bangladesh Med Res Counc Bull 1989, 15:1-7.

7. Ahmad Q, Chowdhury SG, Islam MN, Khan FD, Alam MR, Miah AH: HBsAg amongst unscreened operated patients. Bangladesh Med Res Counc Bull 1991, 17:11-6.

8. Sattar H, Islam MN: Hepatitis B virus markers among the prostitutes of Dhaka. Bangladesh Med Res Counc Bull 1996, 22:8-11.

9. Mahtab MA, Rahman S, Karim MF, Khan M, Foster G, Solaiman S, Afroz S: Epidemiology of hepatitis B virus in Bangladeshi general population. Hepatobiliary Pancreat Dis Int 2008, 7:595-600.

10. Deinhartd F: Serum markers of hepatitis viruses in natural disease and after vaccination. Prog Liver Dis 1982, 7:451-67.

11. Sabin KM, Rahman M, Hawkes S, Ahsan K, Begum L, Black RE, Baqui AH: Sexually transmitted infections prevalence rates in slum communities of Dhaka, Bangladesh. Int J STD AIDS 2003, 14:614-21.

12. Rumi MA, Siddiqui MA, Salam MA, Iqbal MR, Azam MG, Chowdhury AK, Khan AYM, Hasan KN, Hassan MS: Prevalence of infectious diseases and drug abuse among Bangladeshi workers. Southeast Asian J Trop Med Public Health 2000, 31:571-4.

13. Rahman M, Amanullah, Sattar H, Rahman M, Rashid HA, Mollah AS: Seroepidemiological study of hepatitis B virus infection in a village. Bangladseh Med Res Counc Bull 1997, 23:38-41.

14. Khan M, Haq S, Ahmed N, Matin MA: Etiology and clinical profile of hepatocellular carcinoma in Bangladesh. Bangladseh Med Res Counc Bull 1997, 23:16-24.
15. Hawkes S: Commentary: Human immunodeficiency virus and hepatitis in Bangladesh: widespread or targeted prevention strategies? Int J Epidemiol 2001, 30:885-6.

16. Laskar MS, Harada N, Khan F: Prevalence of hepatitis B surface antigen $(\mathrm{HBsAg})$ in Viqarunnessa noon girls'school children in Dhaka, Bangladesh. Cent Eur J Public Health 1997, 5:202-4.

17. Hepatitis C: [http://who.int/mediacentre/factsheets/fs164/en/].

18. Alter $H J$, Seeff $L B$ : Recovery, persistence, and sequelae in hepatitis $C$ virus infection: a perspective on long-term outcome. Semin Liver Dis 2000, 20:17-35.

19. Poynard T, Bedossa P, Opolon P: Natural history of liver fibrosis progression in patients with chronic hepatitis C. Lancet 1997, 349:825-32.

20. Lauer GM, Walker B: Hepatitis C virus infection. N Engl J Med 2001, 345:41-52.

21. Frank C, Mohamed MK, Strickland GT, Lavanchy D, Arthur RR, Magder LS, El Khoby T, Abdel-Wahab Y, Aly Ohn ES, Anwar W, Sallam I: The role of parenteral antischistosomal therapy in the spread of hepatitis $C$ virus in Egypt. Lancet 2000, 355:887-91.

22. Memon Ml, Memon MA: Hepatitis C: an epidemiological review. J Viral Hepat 2002, 9:84-100.

23. Bogaerts J, Ahmed J, Akhter N, Begum N, Rahman M, Nahar S, Van Ranst M, Verhaegen J: Sexually transmitted infections among married women in Dhaka, Bangladesh: unexpected high prevalence of herpes simplex type 2 infection. Sex Transm Infect 2001, 77:114-9.

24. Shirin T, Ahmed T, labal A, Islam M, Islam MN: Prevalence and risk factors of hepatitis $B$ virus, hepatitis $C$ virus, and human immunodeficiency virus infections among drug addicts in Bangladesh.J Health Popul Nutr 2000, 18:145-50.

25. Gibney L, Macaluso M, Kirk K, Hassan MS, Schwebke J, Vermund SH, Choudhury P: Prevalence of infectious diseases in Bangladeshi women living adjacent to a truck stand: HIV/STD/hepatitis/genital tract infections. Sex Transm Infect 2001, 77:344-50.

26. Brooks WA, Breiman RF, Goswami D, Hossain A, Alam K, Saha SK, Nahar K, Nasrin D, Ahmed N, Arifeen SE, Naheed A, Sack DA, Luby S: Invasive pneumococcal disease burden and implications for vaccine policy in urban Bangladesh. Am J Trop Med Hyg 2007, 77:795-801.

27. Brooks WA, Hossain A, Goswami D, Nahar K, Alam K, Ahmed N, Naheed A, Nair GB, Luby S, Breiman RF: Bacteremic typhoid fever in children in an urban slum, Bangladesh. Emerg Infect Dis 2005, 11:326-9.

28. Vranckx R, Muylle L, Meheus A: Hepatitis B core antibody-negative HBsAg carriers. Infection 1989, 17:250-1.

29. Barrera JM, Francis B, Ercilla G, Nelles M, Achord D, Darner J, Lee SR: Improved detection of anti-HCV in post-transfusion hepatitis by a thirdgeneration ELISA. Vox Sang 1995, 68:15-8.

30. Courouce AM, Bouchardeau F, Girault A, Le Marrec N: Significance of NS3 and NS5 antigens in screening for HCV antibody. Lancet 1994, 343:353-4.

31. Richter SS: Laboratory assays for diagnosis and management of hepatitis C virus infection. J Clin Microbiol 2002, 40:4407-12.

32. SPSS: Statistical Package for Social Sciences computer program: Version 10.0. Chicago, II: SPSS Inc 1996.

33. Zaki H, Darmstadt GL, Baten A, Ahsan CR, Saha SK: Seroepidemiology of hepatitis B and delta virus infections in Bangladesh. J Trop Pediatr 2003, 49:371-4.

34. Gibney L, Saquib N, Metzger J, Choudhury P, Siddiqui M, Hassan M: Human immunodeficiency virus, hepatitis B, C and D in Bangladesh's trucking industry: prevalence and risk factors. Int J Epidemiol 2001, 30:878-84.

35. Kim YS, Ahn Y, Kim DW: Familial clustering of hepatitis $B$ and $C$ viruses in Korea. J Korean Med Sci 1994, 9:444-9.

\section{Pre-publication history}

The pre-publication history for this paper can be accessed here: http://www.biomedcentral.com/1471-2334/10/208/prepub

\section{doi:10.1186/1471-2334-10-208}

Cite this article as: Ashraf et al:: Prevalence and risk factors of hepatitis $B$ and $C$ virus infections in an impoverished urban community in Dhaka, Bangladesh. BMC Infectious Diseases 2010 10:208. 